\title{
The Behavioural Paths to Wellbeing: An Exploratory Study to Distinguish Between Hedonic and Eudaimonic Wellbeing From an Activity Perspective
}

\author{
Shijiang Zuo, ${ }^{1,2}$ Shun Wang, ${ }^{1,2}$ Fang Wang, ${ }^{1,2}$ and Xiafei Shi ${ }^{1,2}$ \\ ${ }^{1}$ School of Psychology, Beijing Normal University, Beijing, China \\ 2 Beijing Key Laboratory of Applied Experimental Psychology, Beijing, China
}

\begin{abstract}
$\mathrm{H}$ edonic wellbeing and eudaimonic wellbeing are two prevailing approaches to wellbeing. However, remarkably little research has distinguished them from an activity perspective; the knowledge of behavioural paths for achieving these two wellbeings is poor. This study first clarified the behavioural contents of the two approaches through a bottom-up method and then analysed the representativeness of activities to indicate to what extent activities contributed to wellness. We found that the paths to hedonic wellbeing and eudaimonic wellbeing overlapped and differed from each other. Furthermore, this study explained why hedonic activity differed from eudaimonic activity by analysing activity characteristics. We found that people reported higher frequency, sensory experience, and affective experience in hedonic activity, whereas they reported higher intellectual experience, behavioural experience, and spiritual experience in eudaimonic activity. Finally, we explored the behavioural pattern of wellbeing pursuit in both an unthreatening situation and a threatening situation. We found that the overlap between the two approaches increased in the threatening situation. Moreover, people in the threatening situation tended to score lower on all characteristics except frequency relative to those in the unthreatening situation. It seemed that the behavioural pattern in the threatening situation was less effective than its equivalent in the unthreatening situation.
\end{abstract}

Keywords: hedonic wellbeing, eudaimonic wellbeing, representativeness, activity characteristic, threatening situation

The juxtaposition of hedonic wellbeing and eudaimonic wellbeing has been prevalent in recent psychological research. Rooted in different philosophical traditions, hedonic wellbeing and eudaimonic wellbeing elaborate the essence of a human's wellness in quite different manners (Ryan \& Deci, 2001; Ryan, Huta, \& Deci, 2008). Specifically, the hedonic approach defines wellbeing as happiness and focuses on the positive emotions and life satisfaction (Biswas-Diener, Kashdan, \& King, 2009; Delle Fave, Brdar, Freire, Vella-Brodrick, \& Wissing, 2011; Kahneman, 1999). In contrast, the eudaimonic approach defines wellbeing as meaningfulness and focuses on the meaning in life and the realisation of potential (Baumeister, Vohs, Asker, \& Garbinsky, 2013; Delle Fave et al., 2011; Waterman, 1993). An important issue in the field of wellbeing is to distinguish these two approaches. Researchers propose this exploration can be conducted from different perspectives, such as motivation, functioning, and activity (Huta \& Waterman, 2014). However, most studies on this topic focus on the motivation and functioning of wellbeing, whereas few studies distinguish between hedonic and eudaimonic wellbeing from an activity perspective. Therefore, in this research, we endeavoured to conduct an exploratory study with an activity perspective, with the aim of distinguishing the two approaches.

Motivation analysis and functioning analysis of hedonic wellbeing and eudaimonic wellbeing would benefit us with a better understanding of these two approaches. Motivation analysis concerns the variables that organise the direction of a person's behaviours, such as orientations, values, and goals (Huta \& Waterman, 2014). In this perspective, hedonic wellbeing is present-oriented and linked 
to instinctive needs (such as wealth and power), whereas eudaimonic wellbeing involves integrating past, present, and future and is linked to intrinsic goals and social values (such as personal growth and relationships; Baumeister et al., 2013; Peterson, Park, \& Seligman, 2005; Ryan et al., 2008). On the other hand, functioning analysis is concerned with the physical and psychological functions of hedonic wellbeing and eudaimonic wellbeing (Huta \& Waterman, 2014). In this perspective, researchers believe the functions of eudaimonic wellbeing are richer and more positive than their hedonic wellbeing equivalents (Bauer \& McAdams, 2010; Fredrickson et al., 2013). For example, the main function of hedonic wellbeing is regarded as satisfaction (Diener, Lucas, \& Scollon, 2006). In contrast, the functions of eudaimonic wellbeing are rather complicated: self-determination theory proposes three components of eudaimonic wellbeing, including competence, relatedness, and autonomy (Ryan \& Deci, 2001; Ryan et al., 2008), while psychological wellbeing proposes a sixfunction construction of eudaimonic wellbeing, including autonomy, environmental mastery, personal growth, positive relations with others, purpose in life, and selfacceptance (Ryff, 2013; Ryff \& Singer, 2008).

Nevertheless, neither motivation analysis nor functioning analysis suggest concrete methods of achieving hedonic and eudaimonic wellbeing. How to achieve personal wellbeing is a fundamental question in human life, which is probably the common and ultimate goal of all wellbeing research. As Aristotle claimed, one becomes good by doing good (Cahn, 1990). The pursuit of wellbeing should be embodied in a series of vivid activities throughout life. Clarifying the activities that could contribute to hedonic (vs. eudaimonic) wellbeing is instructive for the public, and this question is actually what activity analysis tries to answer. Therefore, activity analysis aiming to further distinguish between hedonic and eudaimonic wellbeing has value. In this exploratory study, we were interested in: (1) the behavioural contents of hedonic wellbeing and eudaimonic wellbeing; (2) the extent to which a given activity with its behavioural contents contributes to hedonic (or eudaimonic) wellbeing; (3) the differences in the activity characteristics between hedonic activity (HA) and eudaimonic activity (EA); and (4) whether individuals' behavioural pattern of achieving wellbeing shows cross-situational consistency or not (we conducted an activity analysis on both a threatening situation in which an individual has a sense of unhappiness and the paired unthreatening situation). We would next like to address these questions and introduce the methodology adopted in this study.

\section{Behavioural Contents of Hedonic Well-being and Eudaimonic Well-being}

What are the behavioural contents of hedonic wellbeing and eudaimonic wellbeing? It is probably the first question to ask about activity analysis. Some prior studies have worked on this topic to some extent and found valuable results; most have clarified whether some given activities contribute to wellbeing. The earliest relevant works were several intervention studies, usually in which a single activity was proved to contribute to wellbeing, such as forgiveness (McCullough, Pargament, \& Thoresen, 2000), gratitude (Emmons \& McCullough, 2003), and personal strength (Seligman, Steen, Park, \& Peterson, 2005). Subsequently, researchers were inclined to test more than one activity in their research and expanded the scale of activity. Further, a classification was made between HA and EA. For example, after a literature review, Steger, Kashdan, and Oishi (2008) summarised seven typical activities that fully represent HA (such as getting drunk, going to a big party) and seven typical activities that fully represent EA (such as volunteering one's time, giving money to a person in need) and testified to these activities' effects on the promotion of wellbeing. The classification was further refined in the work of Henderson, Knight, and Richardson (2013), who supplied a rather large activity pool and classified activities into four types: hedonic, eudaimonic, both hedonic and eudaimonic, and neither hedonic nor eudaimonic; and discussed the links between these types with various functions (e.g., flourishing).

Prescribing behavioural contents in a study is an efficient technique when we are interested in whether these activities can bring about wellness. However, we argue that this methodology is questionable in this activity analysis. We believe the openness and entirety of behavioural contents are important in studies of activity analysis. First, a prescribed pool of behavioural contents reflects the experts' thinking rather than individuals' real ideas about wellbeing. In fact, each individual has an innate potential to identify a good life, and their perceptions of wellbeing can be different (Diener et al., 2006; Norton, 1976). For this reason, some researchers have criticised the prescription of wellbeing (especially for eudaimonic wellbeing) and advocated to explore the public's understanding of wellbeing (Diener, Sapyta, \& Suh, 1998; Kimiecik, 2011). In addition, although an expert is more likely than an ordinary person to think more often about such matters, it is still likely that some activities would be left out, as individuals' perceptions of wellness are quite different (Diener et al., 2006). Therefore, we considered that establishing a pool of behavioural contents with a bottom-up approach was more reasonable in our study, relative to a prescribed one.

In this study, participants were first instructed to nominate three activities in their life that help them achieve hedonic wellbeing and eudaimonic wellbeing, respectively. In this manner, the specific thinking of each individual would be respected to a great extent. Of course, more activities nominated by each participant result in a greater range of behavioural contents. However, the number was set at three in consideration of the participants' task load. Second, the raw data was coded according to specific rules by experts. This process aims to simplify the text and integrate similar activities. We note that Huta and Ryan (2010) 
asked participants to list activities that contribute to hedonic wellbeing and eudaimonic wellbeing in their study, but the data were not processed systematically and the behavioural contents were redundant. Thus, we believe both participants' nomination and experts' coding are necessary. The combination of these two steps were utilised to establish a pool of behavioural contents.

\section{Representativeness of Activities}

The follow-up question was about the extent a given activity contributes to hedonic (or eudaimonic) wellbeing. Individuals engage in various activities to pursue wellbeing, and their preference for these activities should be distinctive. In this process, some activities would be commonly used whereas others would be rarely used. Meanwhile, it is likely that individuals attach more importance to some activities than others. These phenomena indicate that although both activities contribute to hedonic (or eudaimonic) wellbeing, their representativeness of hedonic (or eudaimonic) wellbeing is probably different. Indeed, some typical activities exist; however, we can also explain the representativeness in another manner. As some researchers have claimed, the behavioural contents of hedonic wellbeing and those of eudaimonic wellbeing may overlap (Huta \& Ryan, 2010). For example, social interaction boosts both hedonic wellbeing and eudaimonic wellbeing at the same time (Myers, 2000; Ryff \& Singer, 2008). The question is whether social interaction is more involved in achieving hedonic wellbeing or eudaimonic wellbeing; although the same activity boosts both types of wellbeing, its representativeness between the approaches of wellbeing is probably different. Thus, some activities are hedoniclike while others are eudaimonic-like. To summarise, the representativeness of activities is embodied in two aspects: the representativeness between activities (in the same approach) and the representativeness between approaches (of the same activity).

Assessment of representativeness is important in this exploratory study, but there are few existing methods that can be consulted in wellbeing studies. Fortunately, there are some inspiring studies in related fields; for example, cognitive psychology. People are usually provided with a category name as a cue and are then required to retrieve instances, which is a process of conceptual expansion (Ward, Smith, \& Vaid, 1997). In this process, the retrievability or 'coming-to-mindedness' of instances is different. Ward $(1994,1995)$ named this property 'representativeness'; he proposed that instances most likely to be retrieved are those that are most representative of the concept. This assumption conforms to human intuition, which simplifies tasks that demand considerable cognitive resources and quickly completes them to reduce the cognitive load (Ward, Patterson, Sifonis, Dodds, \& Saunders, 2002). Similarly, the nomination of HA and EA is also a process of conceptual expansion. The retrievability of behavioural contents could be regarded as representa- tiveness. Representativeness can be influenced by different indicators, such as frequency of occurrence and familiarity. Ward and his colleagues (2002) determined representativeness indices by assessing the frequency with which given items were listed (termed output dominance), their average rank order of appearance across participants' lists (termed rank), and the measure that combined frequency and rank order (termed dominance/rank). These three indices were adopted to assess the representativeness in our study and the representativeness both between activities and between approaches.

\section{Characteristics of HA and EA}

After behavioural contents and representativeness have been addressed, one is likely to inquire which characteristics make HA different from EA. The first two questions may delineate what hedonic wellbeing and eudaimonic wellbeing are in the activity perspective; however, this question aims to explain why these two approaches differ with respect to each other. Different activities possess different features. For example, some activities are more challengeable and require a higher level of skills than others (Huta \& Waterman, 2014). The differences in activity characteristics would potentially reflect individuals' naïve psychology in wellbeing pursuit and suggest a difference between HA and EA.

Few wellbeing studies have previously explored activity characteristics, and the measuring method is relative immature. Huta and Waterman (2014) recommended that activity characteristics can be assessed with self-reports; we followed their suggestion in this study. In addition, the greatest challenge here was how to identify the dimension of activity characteristics. Due to the use of a self-reported method, activity characteristics in this study are presented in the form of individuals' experience; therefore, we first identified the dimension of activity characteristics by consulting the dimensions of experience. In the literatures of philosophy and cognitive science, researchers believe that experiences result from different aspects, such as knowledge and reasoning, doing, perceiving through the senses, feelings and emotions, and so on (Dewey, 2002; Dubé \& Le Bel, 2003; Pinker, 1999). Furthermore, Brakus, Schmitt, and Zarantonello (2009) formulated four dimensions of experience in consumer psychology: intellectual experience, behaviour experience, sensory experience, and affective experience. These experiences are highly relative to activity characteristics: intellectual experience refers to knowledge-using activities such as classifying, analysing, and reasoning about things; behaviour experience refers to the physical actions involved in the activity; sensory experience refers to the sensory perceptions gained in the activity; and affective experience refers to feelings, emotions, and social relationships in the activity. These four indices were part of the dimensions of activity characteristics. In addition, two more dimensions were extracted from wellbeing research: frequency and 
spiritual experience. We think they are effective indices to distinguish between hedonic and eudaimonic wellbeing. Specifically, hedonic wellbeing is associated with satisfaction in the short term whereas eudaimonic wellbeing is linked to fulfillment in the long term (Steger et al., 2008). It implies that, compared to hedonic wellbeing, the achievement of eudaimonic wellbeing is more time consuming but is maintained longer, and people may engage in HA and EA in different frequencies to maintain the wellness. Further, some researchers are interested in the link between spirituality and hedonic and eudaimonic wellbeing (Joshanloo, 2011). Conceptually, hedonic wellbeing focuses on happiness whereas eudaimonic wellbeing focuses on meaningfulness. Obviously, spirituality is a concept closer to meaningfulness rather than happiness. Thus, assessing spiritual experience gained in the activity is valuable. To conclude, six indices were introduced to measure activity characteristics in this study: frequency, intellectual experience, behaviour experience, sensory experience, affective experience, and spiritual experience.

\section{The Impact of Situations on Wellbeing Pursuit}

Finally, we were interested in whether the path to both hedonic and eudaimonic wellbeing is consistent across situations. Substantial evidence shows that people's behavioural pattern will change when they are in a threatening situation. For example, when self-esteem is threatened, people tend to choose goals that are likely to be met (Lambird \& Mann, 2006). Similarly, after the manipulation of mortality salience, people tend to enhance their attachment and promote their identification of cultural worldview (Hart, Shaver, \& Goldenberg, 2005). When encountering a relationship-threatening situation, people also react differently than usual (Simpson, Ickes, \& Grich, 1999). Generally, at least two features exist in the threatening situation: first, the aversive arousal will be evoked and the relief from this bad feeing becomes the prior motivation that would make individuals take compensatory efforts (Heine, Proulx, \& Vohs, 2006; Proulx \& Inzlicht, 2012). Second, individuals' thoughts and actions would become narrower, and the narrowed thoughtaction repertoire would promote quick and decisive action that carries direct and immediate benefit (Fredrickson, 2001). Therefore, it is an interesting question whether the behavioural pattern in wellbeing pursuit will change in a threatening situation - specifically, the wellness threatening situation.

Living a happy life is a basic expectation for all people. However, various issues devastate human wellness, especially the occurrence of disasters and emergencies. Deficiency of wellbeing is a pervasive and challenging task in today's society. Studying the path of rebuilding wellbeing is very valuable for our society. In this study, we aimed to explore the changes and the change pattern of the paths to hedonic wellbeing and eudaimonic wellbeing, includ- ing behavioural contents, representativeness, and activity characteristics, from a normal situation to a situation with deficient wellbeing.

\section{The Current Study}

To summarise, this was an exploratory study of activity analysis that aimed to distinguish between hedonic and eudaimonic wellbeing from an activity perspective. First, we addressed the behavioural contents of hedonic wellbeing and eudaimonic wellbeing through a bottom-up method: participants were instructed to nominate activities, after which we coded the raw data and established pools of HA and EA. Second, the representativeness of activity was examined. Three indices adopted from Ward et al.'s study (2002) were calculated after data collection, including output dominance, rank, and dominance/rank. Meanwhile, representativeness was classified into two types: representativeness between activities served for the recognition of typical HA and EA; representativeness between approaches was used to test whether an activity was hedonic-like or eudaimonic-like. Taken together, the analysis of behavioural contents and representativeness delineate what hedonic wellbeing and eudaimonic wellbeing are. Third, with the aim of uncovering the essential differences between HA and EA, we measured an activity's characteristics. Six kinds of characteristics, including frequency, intellectual experience, behaviour experience, sensory experience, affective experience, and spiritual experience were assessed by self-reports. Fourth, we explored whether the path to hedonic wellbeing and eudaimonic wellbeing was consistent across situations; and the activity analysis was conducted in both an unthreatening situation and a threatening situation.

\section{Method \\ Participants}

Two hundred undergraduate students (31 males; 168 females; 1 not mentioned) were recruited from a psychology course at Beijing Normal University and were offered a course credit as a reward. Participants completed the task in an online system, and the system closed after 100 instances of data were collected in each condition. All participants were Chinese. The average age of the participants is $20.30 \pm 8.26$ years, ranging from 18 to 35 . Participation in the study was voluntary, and all procedures conformed to institutional ethical guidelines for research.

\section{Procedure and Measures}

The participants completed an online survey consisting of two tasks. Half the participants were randomly assigned to an unthreatening situation and the other half were randomly assigned to a threatening situation. First, participants were asked to sequentially nominate three activities in their life that help them achieve hedonic wellbeing and eudaimonic wellbeing, respectively. Participants were instructed not to replicate an activity as far as possible. 
The order of the hedonic condition and eudaimonic condition was counterbalanced. It should be noted that since happiness and meaning were regarded as the essence of the two approaches (Baumeister et al., 2013; Gu, Huang, Zhang, \& Wang, 2015; Xin-qiang, Xiao-lin, Fan, \& Da-jun, 2016), they were used to represent hedonic wellbeing and eudaimonic wellbeing to enable easier understanding. There were two kinds of instructions that were used to manipulate the unthreatening/threatening situation. In the unthreatening situation, participants were instructed to think 'What would you do to make yourself feel happy?' and 'What would you do to make yourself feel meaningful'; in the threatening situation, participants were instructed to think 'When you feel unhappy, what would you do to regain happiness?' and 'When you feel meaningless, what would you do to regain meaning?' Second, participants were asked to rate the characteristics of each activity they had just nominated. Six questions were developed to measure the activity characteristics: 'I engage in this activity very often' targeted frequency; 'I engage in a lot of thinking when I carry out this activity' targeted intellectual experience; 'I engage in physical actions and behaviours when I carry out this activity' targeted behaviour experience; 'This activity induces feelings and sentiments' targeted affective experience; 'This activity makes a strong impression on my visual sense or other senses' targeted sensory experience; and 'Engaging in this activity makes me feel that I am a spiritual being (an integral part of the universe)' targeted spiritual experience. In the system, the nominated activities were represented one after the other; and each time participants rated all six questions with a ranking from $1=$ strongly disagree to 7 = strongly agree.

\section{Coding}

Two coders coded the raw data together. A revised coding method, derived from grounded theory (Glaser \& Strauss, 2009), was applied in the current study. The coding was a complicated process of sense making. On the one hand, it was expected to detect the actual content of what the participants listed; on the other hand, it should draw upon the underlying linkages among the activities (Liu, 2008).

The process included three steps. All activities $(1,200$ in total) were coded together. In the first step, unrelated details were deleted and related information was kept. Then, the coders named each activity with a serial number. Similar activities shared the same number. In the second step, the coders inductively sought and summed the themes and linkages from the named activities. The significance of each named activity was analysed. In the third step, significant named activities were determined one by one. If another named activity had evident linkages with a significant one, it was integrated into the significant activity. Meanwhile, the themes and linkages were created and revised throughout the integration. These procedures were cycled through several times until each activity reflected its independence.

\section{Results}

\section{Behavioral Contents}

After the process of coding, 19 categories of activities remained. Their names, descriptions, and examples are presented in Table 1. Generally, activities coded into the same category had strong linkages whereas those in different categories had weak connections. However, we did not assume that the distances between each of the two categories were equal; indeed, some categories had more in common than others. For example, both reading and academic learning referred to book reading, and both striving and task fulfillment involved individual effort. For these cases, the standard to distinguish them was drawn from the motivation and construal levels. The coders took these factors into consideration when creating the themes and linkages. Textbook reading aimed to master professional knowledge, whereas reading a fictional book was obviously not similarly motivated; therefore, textbook reading was classified into academic learning and fictional reading was not. Similarly, personal effort in striving was long term and served abstract goals whereas task fulfillment was usually short term and served concrete goals. Therefore, the former was labelled as striving and the latter was classified into another category.

In the unthreatening situation, the pool of behavioural contents covered all of the 19 categories: HA consisted of 17 categories (all except social practice and acquiring information); EA consisted of 18 categories (all except contemplation). In the threatening situation, the pool of behavioural contents consisted of 18 categories (all except religious activity): HA consisted of 12 categories while EA consisted of 18 categories therein. The result showed there were great overlaps of behavioural contents between hedonic wellbeing and eudaimonic wellbeing, both in the unthreatening situation and threatening situation. It indicated that the activities helping people achieve hedonic wellbeing and eudaimonic wellbeing were quite similar across a wide range of behaviours.

\section{Representativeness Between Activities}

The analysis of behavioural contents detailed a great variety of activities that contributed to participants' wellness. However, it did not explain to what extent a specific activity contributed to hedonic wellbeing and eudaimonic wellbeing. The behavioural contents given above were excessive and the typical activities of HA and EA were not indicated. Therefore, we next calculated the representativeness of each activity.

The three indices included output dominance, rank, and dominance/rank. It should be noted that there were two types of values of representativeness in our study: values by sample and values by case. Values by sample were mainly used in the descriptive statistics. They concerned how typical a category was within the range of all participants: output dominance counted the frequency of each category being nominated across all the 
Table 1

Description of Behavioural Contents

\begin{tabular}{|c|c|c|}
\hline Activity category & Description & Example \\
\hline Academic learning & Learning professional courses voluntarily & Having lessons, conducting experiments \\
\hline Acquiring information & Gaining information about the world & Watching news \\
\hline Altruism & Helping others when they get in trouble & Donating, comforting others \\
\hline Caring for friends and family & Doing something for family and friends to express care & Cooking for family, Buying presents for friends \\
\hline Cleaning and chores & Cleaning rooms and washing something & Cleaning up, tidying the room \\
\hline Contemplation & Thinking about life & Reflecting on the past, thinking about the future \\
\hline Communication & Contacting or spending time with others & Chatting, having a party \\
\hline Entertainment & Seeking sensual pleasure & Having a meal, playing games, listening to music, watching TV \\
\hline Hobbies & Engaging in favoured skills except sports & Drawing, writing, making crafts \\
\hline Physical exercise & Doing sports and exercising & Running, playing football, keeping fit \\
\hline Reading & Reading books except textbooks and articles & Reading history, reading novels \\
\hline Relaxation & Sleeping, relaxing and being in a daze & Sleeping, showering \\
\hline Religious activity & Doing something related to one's religion & Attending church, praying \\
\hline Social practice & Joining clubs and take part in social activities & Joining clubs, attend in social activities \\
\hline Striving & Acting toward or realising a dream & Taking efforts toward a dream; realising a dream. \\
\hline Task fulfillment & Completing tasks passively & Finishing homework, completing tasks \\
\hline Task reward & Being admired or rewarded after a good performance & Getting investment returns, getting ideal grades after efforts \\
\hline Travel & Travelling around and enjoying scenery & Traveling, being close to nature \\
\hline Working for self-sufficiency & Working (part-time) for self-sufficiency & Working for money \\
\hline
\end{tabular}

participants (a high value of output dominance means the corresponding category was a common method of wellbeing pursuit); rank assessed each category's average rank order across all the participants (a low value of rank means the corresponding category was a preferred method of wellbeing pursuit); and dominance/rank combined the two indices above (a high value of dominance/rank means the category was representative overall). In contrast, values by case were mainly used in the comparison test. They concerned how typical a category was in every single individual. For each category, every participant received a specific value thereof: the output dominance and rank was calculated in every case, and each time only one category was analysed; the value of dominance/rank was recoded as zero if no target activity was found in a case and finally ranged from $0-1.5$.

For representativeness, values by sample are presented in Table 2. These values revealed how representative a specific category was in the pools HA and EA. We further simplified the pools through output dominance because the pools were bloated and infrequent activities distracted our attention and were susceptible to measuring error. We took a standard that successively accumulated dominant categories until over $85 \%$ variance was accounted for. As a result, in the unthreatening situation, we identified seven typical categories of HA and nine typical categories of EA: the typical categories of HA were entertainment, communication, travel, reading, task reward, relaxation, and hobbies; and the typical categories of EA were altruism, reading, academic learning, caring for friends and family, communication, travel, striving, physical exercise, and hobbies. In the threatening situation, we identified five typical categories of HA and ten typical categories of EA: the typical categories of HA were entertainment, communication, relaxation, physical exercise, and reading; and the typical categories of EA were reading, academic learning, enter- tainment, contemplation, communication, altruism, physical exercise, task fulfilment, hobbies, and travel. These categories were considered to be the most typical activities that helped participants to achieve hedonic wellbeing and eudaimonic wellbeing, respectively. In both the unthreatening situation and threatening situation, we found that the typical categories of HA were different from those of EA; but at the same time, they also partly overlapped. In summary, some activities contributed to only one approach (hedonic wellbeing or eudaimonic wellbeing) whereas some activities contributed to two approaches (see Table 3).

After simplification of the pools, we explored whether the representativeness of an activity decreased or increased across situations. Here, values by case of representativeness were used. Only dominance/rank was used to conduct a comparison test since this index combined with output dominance and rank. If only one category was included in one of the simplified pools, it would be analysed. For all categories analysed, their distributions of dominance/rank were skewed. Nevertheless, the sample size was large enough to conduct an independent sample $t$ test. The results of the $t$ test are presented in Table 4. For hedonic wellbeing, the representativeness of entertainment $(t=-$ $5.56, p<.001)$ and physical exercise $(t=-2.00, p=.047)$ in the threatening situation was significantly higher than the unthreatening situation; but the representativeness of communication $(t=2.44, p=.016)$, travel $(t=2.35, p=$ $.020)$, and task reward $(t=3.81, p<.001)$ in the threatening situation was significantly lower than the unthreatening situation. For eudaimonic wellbeing, the representativeness of reading $(t=-2.15, p=.033)$, entertainment $(t=-3.83, p<.001)$, contemplation $(t=-4.14, p<.001)$, and task fulfillment $(t=-2.12, p=.036)$ in the threatening situation was significantly higher than the unthreatening situation; but the representativeness of altruism $(t=5.33$, 
Table 2

The Values by Sample for Representativeness

\begin{tabular}{|c|c|c|c|c|c|c|c|c|c|c|c|c|}
\hline \multirow[b]{3}{*}{ Activity category } & \multicolumn{6}{|c|}{ Unthreatening situation } & \multicolumn{6}{|c|}{ Threatening situation } \\
\hline & \multicolumn{3}{|c|}{ Hedonic } & \multicolumn{3}{|c|}{ Eudaimonic } & \multicolumn{3}{|c|}{ Hedonic } & \multicolumn{3}{|c|}{ Eudaimonic } \\
\hline & $d$ & $r$ & $d / r$ & $d$ & $r$ & $d / r$ & $d$ & $r$ & $d / r$ & $d$ & $r$ & $d / r$ \\
\hline Academic learning & 5 & 1.60 & 3.13 & 45 & 2.02 & 22.25 & - & - & - & 38 & 2.13 & 17.83 \\
\hline Acquiring information & - & - & - & 2 & 2.00 & 1.00 & - & - & - & 2 & 2.00 & 1.00 \\
\hline Altruism & 6 & 2.33 & 2.57 & 60 & 1.83 & 32.73 & 1 & 1.00 & 1.00 & 21 & 2.14 & 9.80 \\
\hline Caring for friends and family & 6 & 1.50 & 4.00 & 22 & 2.50 & 8.80 & 1 & 1.00 & 1.00 & 3 & 2.67 & 1.13 \\
\hline Cleaning and chores & 1 & 2.00 & 0.50 & 3 & 1.67 & 1.80 & 2 & 2.00 & 1.00 & 9 & 2.11 & 4.26 \\
\hline Contemplation & 2 & 1.00 & 2.00 & - & - & - & 7 & 2.29 & 3.06 & 27 & 2.07 & 13.02 \\
\hline Communication & 85 & 2.00 & 42.50 & 18 & 2.00 & 9.00 & 60 & 2.02 & 29.75 & 22 & 2.50 & 8.80 \\
\hline Entertainment & 89 & 2.03 & 43.76 & 5 & 2.20 & 2.27 & 142 & 1.91 & 74.41 & 27 & 2.11 & 12.79 \\
\hline Hobbies & 14 & 2.14 & 6.53 & 10 & 1.80 & 5.56 & 9 & 2.00 & 4.50 & 16 & 2.13 & 7.53 \\
\hline Physical exercise & 9 & 1.89 & 4.76 & 15 & 2.33 & 6.43 & 20 & 2.05 & 9.76 & 21 & 2.29 & 9.19 \\
\hline Reading & 19 & 1.58 & 12.03 & 52 & 1.58 & 32.98 & 16 & 2.13 & 7.53 & 64 & 1.44 & 44.52 \\
\hline Relaxation & 14 & 2.29 & 6.13 & 2 & 3.00 & 0.67 & 26 & 2.19 & 11.86 & 9 & 2.44 & 3.68 \\
\hline Religious activity & 1 & 1.00 & 1.00 & 2 & 1.50 & 1.33 & - & - & - & - & - & - \\
\hline Social practice & - & - & - & 8 & 2.25 & 3.56 & - & - & - & 1 & 2.00 & 0.50 \\
\hline Striving & 3 & 1.67 & 1.80 & 17 & 2.53 & 6.72 & - & - & - & 3 & 2.67 & 1.13 \\
\hline Task fulfillment & 4 & 2.25 & 1.78 & 7 & 1.86 & 3.77 & 3 & 1.67 & 1.80 & 17 & 1.71 & 9.97 \\
\hline Task reward & 17 & 2.41 & 7.05 & 8 & 2.00 & 4.00 & - & - & - & 2 & 1.50 & 1.33 \\
\hline Travel & 22 & 1.95 & 11.26 & 17 & 2.29 & 7.41 & 13 & 2.38 & 5.45 & 11 & 2.18 & 5.04 \\
\hline Working for self-sufficiency & 3 & 2.00 & 1.50 & 7 & 2.14 & 3.27 & - & - & - & 7 & 1.86 & 3.77 \\
\hline
\end{tabular}

Note: $d, r, d / r$ are the output dominance, rank, dominance/rank, respectively.

\section{Table 3}

Typical Activities After Simplification

\begin{tabular}{ll}
\hline Types & Activity category \\
\hline $\begin{array}{l}\text { Unthreatening situation } \\
\text { Typical in HA } \\
\text { Typical in EA }\end{array}$ & $\begin{array}{c}\text { Entertainment, task reward, and relaxation } \\
\text { Altruism, academic learning, caring for friends } \\
\text { and family, striving and physical exercise } \\
\text { Communication, travel, reading and hobbies }\end{array}$ \\
$\begin{array}{l}\text { Typical in both } \\
\text { Threatening situation } \\
\text { Typical in HA }\end{array}$ & $\begin{array}{l}\text { Relaxation } \\
\text { Typical in EA }\end{array}$ \\
$\begin{array}{c}\text { Academic learning, contemplation, altruism, } \\
\text { task fulfillment, hobbies and travel }\end{array}$ \\
Typical in both & $\begin{array}{c}\text { Entertainment, communication, physical } \\
\text { exercise and reading }\end{array}$ \\
\hline
\end{tabular}

Note: $\mathrm{HA}=$ hedonic activity, $\mathrm{EA}=$ eudaimonic activity.

$p<.001)$, caring for friends and family $(t=3.73, p<.001)$, and striving $(t=2.97, p=.004)$ in the threatening situation was significantly lower than the unthreatening situation. Generally, the paths of wellbeing pursuit changed over situations for both hedonic wellbeing and eudaimonic wellbeing. It seemed that the activities that carried direct and immediate benefit on relieving aversive feelings (e.g., entertainment) were more preferred in the threatening situation, whereas activities that required long-term efforts (e.g., striving) and activities that involved social interaction (e.g., communication) were less preferred.

\section{Representativeness Between Approaches}

The same activity may contribute to both hedonic wellbeing and eudaimonic wellbeing, but whether it was hedonic-like or eudaimonic-like was still unclear. Therefore, we next compared each activity's representativeness

\section{Table 4}

$t$-Test Results of Representativeness Between Activities Across Situations

\begin{tabular}{lrrrc}
\hline Activity category & $d f$ & $M$ & $S D$ & \multicolumn{1}{c}{$t$} \\
\hline Hedonic wellbeing & & & & \\
Communication & 198.00 & .146 & .060 & $2.44^{*}$ \\
Entertainment & 198.00 & -.358 & .064 & $-5.56^{* * *}$ \\
Hobbies & 198.00 & .029 & .029 & .98 \\
Physical exercise & 174.88 & -.065 & .032 & $-2.00^{*}$ \\
Reading & 183.69 & .052 & .041 & 1.27 \\
Relaxation & 182.13 & -.061 & .035 & -1.74 \\
Task reward & 99.00 & .083 & .022 & $3.81^{* * *}$ \\
Travel & 154.60 & .081 & .035 & $2.35^{*}$ \\
Eudaimonic wellbeing & & & & \\
Academic learning & 198.00 & .047 & .050 & .93 \\
Altruism & 160.60 & .281 & .053 & $5.33^{* * *}$ \\
Caring for friends and family & 117.75 & .086 & .023 & $3.73^{* * *}$ \\
Contemplation & 99.00 & -.147 & .035 & $-4.14^{* * *}$ \\
Communication & 198.00 & .017 & .033 & .51 \\
Entertainment & 120.97 & -.124 & .033 & $-3.83^{* * *}$ \\
Hobbies & 198.00 & -.018 & .034 & -.55 \\
Physical exercise & 187.49 & -.035 & .029 & -1.21 \\
Reading & 198.00 & -.135 & .063 & $-2.15^{*}$ \\
Striving & 120.35 & .064 & .022 & $2.97^{* *}$ \\
Task fulfillment & 169.40 & -.073 & .035 & $-2.12^{*}$ \\
Travel & 198.00 & .022 & .028 & .76 \\
\hline
\end{tabular}

Note: *parameter significant at $p<.05 ;{ }^{* *}$ parameter significant at $p<.01 ; * * *$ parameter significant at $p<.001$, the same below.

between approaches. If only one category was included in one of the simplified pools, it was analysed. Values by case of dominance/rank were used in the test. For all categories analysed, their distributions of dominance/rank were skewed. Nevertheless, the sample size was large enough to conduct a paired sample $t$ test.

The results of the $t$ test are presented in Table 5. The results showed that in the unthreatening situation, the 


\section{Table 5}

$t$-Test Results of Representativeness Between Approaches in Both Situations

\begin{tabular}{|c|c|c|c|c|}
\hline Activity category & $d f$ & $M$ & $S D$ & $t$ \\
\hline \multicolumn{5}{|l|}{ Unthreatening situation } \\
\hline Academic learning & 99 & -0.22 & 0.38 & $-5.80 * * *$ \\
\hline Altruism & 99 & -0.36 & 0.49 & $-7.30^{* *}$ \\
\hline Caring for friends and family & 99 & -0.05 & 0.28 & -1.78 \\
\hline Communication & 99 & 0.39 & 0.53 & $7.32 * * *$ \\
\hline Entertainment & 99 & 0.44 & 0.48 & $9.11^{* * *}$ \\
\hline Hobbies & 99 & 0.01 & 0.28 & 0.41 \\
\hline Reading & 99 & -0.25 & 0.58 & $-4.26 * * *$ \\
\hline Relaxation & 99 & 0.07 & 0.21 & $3.23^{* *}$ \\
\hline Physical exercise & 99 & -0.02 & 0.24 & -0.68 \\
\hline Striving & 99 & -0.05 & 0.22 & $-2.39 *$ \\
\hline Task reward & 99 & 0.04 & 0.29 & 1.27 \\
\hline Travel & 99 & 0.06 & 0.37 & 1.58 \\
\hline \multicolumn{5}{|l|}{ Threatening situation } \\
\hline Academic learning & 99 & -0.21 & 0.34 & $-6.32 * * *$ \\
\hline Altruism & 99 & -0.10 & 0.29 & $-3.45^{* *}$ \\
\hline Contemplation & 99 & -0.11 & 0.33 & $-3.38^{* *}$ \\
\hline Communication & 99 & 0.26 & 0.40 & $6.43^{* * *}$ \\
\hline Entertainment & 99 & 0.67 & 0.51 & $13.17^{* * *}$ \\
\hline Hobbies & 99 & -0.04 & 0.25 & -1.41 \\
\hline Reading & 99 & -0.43 & 0.51 & $-8.42^{* * *}$ \\
\hline Relaxation & 99 & 0.09 & 0.30 & $3.04^{* *}$ \\
\hline Physical exercise & 99 & 0.01 & 0.31 & 0.43 \\
\hline Task fulfillment & 99 & -0.10 & 0.32 & $-2.99 * *$ \\
\hline Travel & 99 & 0.00 & 0.23 & -0.07 \\
\hline
\end{tabular}

representativeness of entertainment $(t=9.11, p<.001)$, communication $(t=7.32, p<.001)$, and relaxation $(t=$ $3.23, p=.002$ ) in the hedonic approach was significantly higher than the eudaimonic approach, and thus these activities were hedonic-like; the representativeness of altruism $(t=-7.30, p<.001)$, academic learning $(t=-5.80, p<$ $.001)$, reading $(t=-4.26, p<.001)$, and striving $(t=-2.39$, $p=.019)$ in the hedonic approach was significantly lower than the eudaimonic approach, and thus these activities were eudaimonic-like; the representativeness of caring for friends and family $(t=-1.78, p=.079)$, hobbies $(t=0.41$, $p=.683)$, physical exercise $(t=-0.68, p=.497)$, task reward $(t=1.27, p=.207)$, and travel $(t=1.58, p=.118)$ in the two approaches had no significant differences, and thus these activities were not oriented between hedonic wellbeing and eudaimonic wellbeing.

In the threatening situation, the representativeness of entertainment $(t=13.17, p<.001)$, communication $(t=6.43, p<.001)$, and relaxation $(t=3.04, p=.003)$ in the hedonic approach was significantly higher than the eudaimonic approach, and thus these activities were hedonic-like; the representativeness of reading $(t=-8.42$, $p<.001)$, academic learning $(t=-6.32, p<.001)$, altruism $(t=-3.45, p=.001)$, and contemplation $(t=$ $-3.38, p=.001)$ in the hedonic approach was significantly lower than the eudaimonic approach, and thus these activities were eudaimonic-like; the representativeness of hobbies $(t=-1.41, p=.161)$, physical exercise $(t=$ $0.43, p=.671)$, and travel $(t=-0.07, p=.943)$ in the two approaches had no significant differences, and thus these

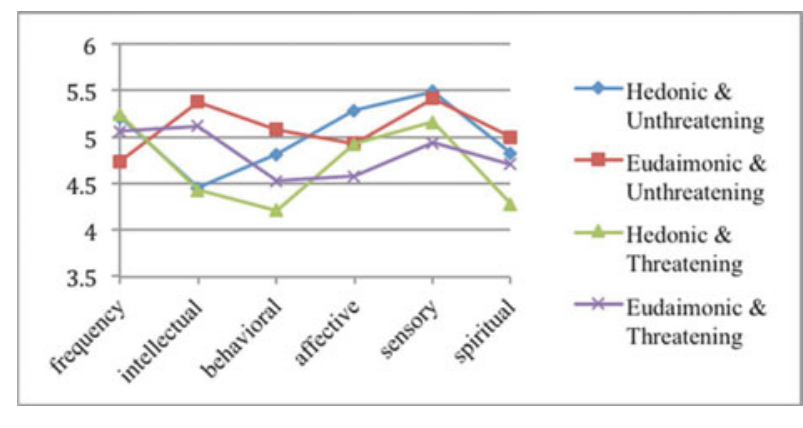

Figure 1

The means of activity characteristics in different conditions.

activities were not oriented between hedonic wellbeing and eudaimonic wellbeing.

Generally, the results revealed that some activities probably contribute to both hedonic wellbeing and eudaimonic wellbeing, but their representativeness between the two approaches may be different. Although some activities were occasionally used to achieve hedonic wellbeing, they played a more important role in the pursuit of eudaimonic wellbeing, whereas this relation reversed in some activities. In any case, the orientation of activities seemed to be stable across situations.

\section{Activity Characteristics}

Next, we analysed the activity characteristics, in order to explain why hedonic wellbeing was different from eudaimonic wellbeing and why these two approaches also partly overlapped. In addition, the change of characteristics across situations was also analysed. For each case, every characteristic had three values in the hedonic approach and three values in the eudaimonic approach. We averaged the values with equal weights according to the approaches before analysis. The mean values of activity characteristics in each condition are presented in Figure 1. The distributions of frequency and behavioural experience were skewed; we performed a parametric repeated measures ANOVA since the sample size was adequately large.

The results of the repeated measures ANOVA (see Table 6) showed that the main effect of wellbeing approach was significant in frequency $\left(F=18.56, p<.001, \eta^{2}=.086\right)$, intellectual experience $\left(F=82.31, p<.001, \eta^{2}=.294\right)$, behavioural experience $\left(F=12.01, p=.001, \eta^{2}=.057\right)$, sensory experience $\left(F=17.73, p<.001, \eta^{2}=.082\right)$, and spiritual experience $\left(F=15.45, p<.001, \eta^{2}=.072\right)$; the main effect of wellbeing approach was marginally significant in affective experience $\left(F=3.45, p=.065, \eta^{2}=.017\right)$. In the unthreatening situation, the results of the $t$ test showed that frequency $(t=4.41, p<.001)$ and sensory experience $(t=3.02, p=.003)$ in HA were significantly higher than their equivalents in EA; intellectual experience $(t=-7.10$, $p<.001)$ and behavioural experience $(t=-2.32, p=.022)$ in HA were significantly lower than in EA; no difference was found for affective experience $(t=-0.60, p=.551)$ and 
Table 6

Descriptive Statistics of Activity Characteristics and the Results of Repetitive Measurement

\begin{tabular}{|c|c|c|c|c|c|c|c|}
\hline \multirow[b]{2}{*}{ Dependent variable } & \multicolumn{2}{|c|}{$\begin{array}{c}\text { Unthreatening } \\
\text { situation } M(S D)\end{array}$} & \multicolumn{2}{|c|}{$\begin{array}{c}\text { Threatening } \\
\text { situation } M(S D)\end{array}$} & \multirow[b]{2}{*}{$\begin{array}{l}\text { Approach } \\
\text { Fvalue }\end{array}$} & \multirow[b]{2}{*}{$\begin{array}{l}\text { Situation } \\
F \text { value }\end{array}$} & \multirow{2}{*}{$\begin{array}{l}\text { Approach* } \\
\text { Situation } F \\
\text { value }\end{array}$} \\
\hline & $\begin{array}{l}\text { Hedonic } \\
\text { approach }\end{array}$ & $\begin{array}{l}\text { Eudaimonic } \\
\text { approach }\end{array}$ & $\begin{array}{l}\text { Hedonic } \\
\text { approach }\end{array}$ & $\begin{array}{l}\text { Eudaimonic } \\
\text { approach }\end{array}$ & & & \\
\hline Frequency & $5.21(1.00)$ & $4.74(0.95)$ & $5.24(0.85)$ & $5.06(0.93)$ & $18.56^{* * *}$ & 2.53 & $3.72^{\mathrm{a}}$ \\
\hline Intellectual experience & $4.45(1.07)$ & $5.38(0.93)$ & $4.43(1.12)$ & $5.12(1.02)$ & $82.31^{* * *}$ & 1.41 & 1.67 \\
\hline Behavioral experience & $4.81(1.08)$ & $5.08(1.04)$ & $4.21(1.27)$ & $4.53(1.11)$ & $12.01^{* *}$ & $18.05^{* * *}$ & 0.11 \\
\hline Sensory experience & $5.28(1.05)$ & $4.93(1.14)$ & $4.92(1.14)$ & $4.58(1.23)$ & $17.73^{* * *}$ & $6.60^{*}$ & 0.04 \\
\hline Affective experience & $5.49(0.93)$ & $5.42(0.86)$ & $5.16(1.13)$ & $4.94(1.08)$ & $3.45^{b}$ & $11.57^{* *}$ & 1.01 \\
\hline Spiritual experience & $4.82(1.20)$ & $5.00(1.07)$ & $4.28(1.34)$ & $4.71(1.28)$ & $15.45^{* * *}$ & $7.08^{* *}$ & 2.50 \\
\hline
\end{tabular}

Note: ${ }^{\text {a }}$ statistical significance is $p=.055$; ${ }^{b}$ statistical significance is $p=.065$.

spiritual experience $(t=-1.70, p=.092)$. In the threatening situation, the results of the $t$ test showed that sensory experience $(t=2.93, p=.004)$ and affective experience $(t=2.04$, $p=.044)$ in HA were significantly higher than EA, whereas intellectual experience $(t=-5.69, p<.001)$, behavioural experience $(t=-2.57, p=.012)$, and spiritual experience $(t$ $=-3.81, p<.001)$ in HA were significantly lower than EA; no difference was found for frequency $(t=1.68, p=.095)$.

The main effect of situation was significant in behavioural experience $\left(F=18.05, p<.001, \eta^{2}=.084\right)$, sensory experience $\left(F=6.60, p=.011, \eta^{2}=.032\right)$, affective experience $\left(F=11.57, p=.001, \eta^{2}=.055\right)$, and spiritual experience $\left(F=7.08, p=.008, \eta^{2}=.035\right)$, and was not significant in frequency $\left(F=2.53, p=.113, \eta^{2}=.013\right)$ and intellectual experience $\left(F=1.41, p=.237, \eta^{2}=.007\right)$. In the hedonic approach, the results of the $t$ test showed that behavioural experience $(t=3.62, p<.001)$, sensory experience $(t=2.34, p=.020)$, affective experience $(t=$ $2.23, p=.027)$, and spiritual experience $(t=2.98, p=.003)$ in the threatening situation were lower than the unthreatening situation; no significant difference was found for frequency $(t=-0.23, p=.819)$ and intellectual experience $(t=0.15, p=.880)$. In the eudaimonic approach, the $t$ test results showed that frequency $(t=-2.39, p=.018)$ in the threatening situation was higher than its equivalent in the unthreatening situation; behavioural experience $(t=3.60$, $p<.001)$, sensory experience $(t=2.11, p=.036)$, and affective experience $(t=3.50, p=.001)$ in the threatening situation were significantly lower than the unthreatening situation; intellectual experience $(t=1.83, p=.069)$ and spiritual experience $(t=1.73, p=.084)$ in the threatening situation were marginally higher than the unthreatening situation.

Generally, we found that the characteristics between HA and EA were different. In both situations, participants had higher sensory experience in HA, and higher intellectual experience and behavioural experience in EA. When faced with threats to wellbeing, participants had higher affective experience in $\mathrm{HA}$ and higher spiritual experience in EA, and the difference of frequency between the approaches disappeared. Moreover, we found that activity characteristics obviously decreased in the threatening situation; participants rated lower scores in nearly all indices except frequency. It implied that the paths to wellbeing pursuit in the threatening situation were less effective and less efficient compared to the unthreatening situation, and thus more frequent actions were required as compensatory efforts.

\section{Discussion}

The present study explored the differences and similarities between hedonic wellbeing and eudaimonic wellbeing from an activity perspective. In the beginning, we clarified the behavioural contents of the two types of wellbeing through a bottom-up method. Surprisingly, we found that most activities used to achieve hedonic wellbeing or eudaimonic wellbeing were also considered to be the paths to one another. For example, in a total of 19 categories, 16 categories were shared by hedonic wellbeing and eudaimonic wellbeing in the unthreatening situation. The overlap still remained after we simplified the primary pools of behavioural contents on the basis of representativeness between activities. We found that typical HA and typical EA partly overlapped, and some activities, such as physical exercise and travel, showed no orientation between hedonic wellbeing and eudaimonic wellbeing, which means they equally contributed to the two types of wellbeing. Therefore, we found that there were similarities between hedonic wellbeing and eudaimonic wellbeing. Most prior studies were committed to clarifying the differences between the two approaches while the similarities between them were underestimated. Hedonic wellbeing and eudaimonic wellbeing have different viewpoints, but they are definitely related to each other since both of them concern the wellness of human beings (Baumeister et al., 2013; Keyes, Shmotkin, \& Ryff, 2002). In fact, statistical analyses have revealed that the assessments of the two approaches had high covariance (Bauer, McAdams, \& Pals, 2008; Gallagher, Lopez, \& Preacher, 2009). Some researchers propose that people will achieve hedonic wellbeing in the process of achieving eudaimonic wellbeing (Waterman, Schwartz, \& Conti, 2008). This evidence implied that hedonic wellbeing and eudaimonic wellbeing were positively related to each other. The present research helped to 
further extend the literature on the similarities between the two approaches.

Nevertheless, the differences between hedonic wellbeing and eudaimonic wellbeing are noticeable. In the simplified pools, we found that typical HA differed from typical EA to a great extent. For example, in the unthreatening situation, activities such as entertainment and relaxation contributed only to hedonic wellbeing whereas activities such as altruism and academic learning contributed only to eudaimonic wellbeing. Moreover, the analysis of representativeness between approaches showed that some activities, such as communication and reading, had an orientation between the two approaches, although these activities were used to pursue both hedonic wellbeing and eudaimonic wellbeing. These findings imply that hedonic wellbeing and eudaimonic wellbeing are different on the level of behaviours. In the past, researchers have focused mainly on motivation and functioning to distinguish the two approaches (e.g., Huta \& Ryan, 2010; Ryan et al., 2008). This research found that not only their motivation and functioning, but also people's methods to achieve hedonic wellbeing and eudaimonic wellbeing, were different.

Furthermore, the findings in activity characteristics benefitted a better understanding of the distinctions between hedonic wellbeing and eudaimonic wellbeing. As a whole, we found that people had higher sensory experience and affective experience, and engaged in HA more frequently, whereas they reported higher intellectual experience, behavioural experience, and spiritual experience in EA. We think these distinctions are consistent with the two approaches' specific core opinions. From the aspect of its conceptual nature, hedonic wellbeing stresses the attainment of positive emotions and avoidance of negative emotions (Biswas-Diener et al., 2009; Kahneman, 1999). The importance of emotions in hedonic wellbeing was especially reflected by high affective experience in HA. In contrast, eudaimonic wellbeing stresses the achievement of meaning and potentials (Ryff, 2013; Ryff \& Singer, 2008). Spirituality is a concept much closer to eudaimonic wellbeing, and thus high spiritual experience in EA reflected the importance of spirituality in eudaimonic wellbeing. From the aspect of value orientation, hedonic wellbeing is linked to phylogenetically older systems that are in charge of instincts (Baumeister et al., 2013; Steger \& Shin, 2012). Compared to objects related to deep values, superficial and direct stimuli are more likely to satisfy individuals' instinctive needs. High affective experience in HA increased evidence to support this view. Contrary to hedonic wellbeing, eudaimonic wellbeing is linked to advanced brain systems that are in charge of social values (Baumeister et al., 2013; Steger \& Shin, 2012). The achievement of goals related to social values is a long and arduous process. High intellectual experience and behavioural experience in EA indicated that superficial stimuli helped very little to promote meaning. If activity only involves sufficient thinking and practice, it could be an effective means to achieve goals related to social values. From the aspect of timeli- ness, the attainment of happiness is much easier than that of meaning (Steger et al., 2008); meanwhile, the maintenance of happiness is much shorter than that of meaning. As a result, people have to engage in HA frequently, to maintain transient happiness. The differences in activity characteristics explained the actual aspects that make HA differ from EA.

In addition, this research explored the behavioural pattern of wellbeing pursuit in both an unthreatening situation and a threatening situation. We found that the behaviour patterns between these two situations were different. First, the behavioural contents of wellbeing between the unthreatening situation and threatening situation were different. In the simplified pools, we found that the overlaps between HA and EA were greater in the threatening situation than the unthreatening situation. Most typical HA in the pool were also considered to be typical EA in the threatening situation. This result manifested that hedonic wellbeing and eudaimonic wellbeing became closer to each other and their difference decreased in the threatening situation. The features originating from the threat situation could explain the phenomenon. A threat situation may evoke aversive arousal and motivate individuals to relieve their negative feelings (Proulx \& Inzlicht, 2012). The motivation of relieving arousal could find evidence from a great variety of theories, such as cognitive dissonance theory (Brehm, 2007), terror management theory (Burke, Martens, \& Faucher, 2010), compensatory control theory (Shepherd, Kay, Landau, \& Keefer, 2011), meaning maintenance model (Heine et al., 2006). Due to the presence of this motivation, people have to consider how to relieve their aversive feelings in the process of wellbeing pursuit; and when mixed with this motivation, the methods of rebuilding hedonic wellbeing and eudaimonic wellbeing possibly became more similar. Another feature originating from a threat situation is that people will encounter restriction in information processing; for example, a narrowing in the field of attention (Staw, Sandelands, \& Dutton, 1981). It is possible that people were unable to come up with abundant means of wellbeing pursuit, and thus hedonic wellbeing and eudaimonic wellbeing became similar. Second, people had different behavioural preferences in the unthreatening situation and threatening situation. We found that the representativeness of some activities changed across situations. Some activities were more preferred in the threatening situation, such as entertainment and physical exercise in the hedonic approach, and reading and task fulfillment in the eudaimonic approach; whereas other activities became less preferred in the threatening situation, such as communication in the hedonic approach, and altruism, striving, and caring for friends and family in the eudaimonic approach. When faced with a threat, people usually have a sense of losing control (Shepherd et al., 2011; Staw et al., 1981). Therefore, in the process of wellbeing pursuit, choosing activities with high controllability and abandoning activities with low controllability should be 
a reasonable judgment. Indeed, we noticed that the activities that became more preferred embodied high controllability empirically as people can control the progress and result of these activities. In contrast, the activities that became less preferred usually involved social interactions in which people cannot control the progress and result independently. Moroever, threat also causes ego depletion, and thus people feel a lack of mental energy to participate in demanding activities like striving (Baumeister, Bratslavsky, Muraven, \& Tice, 1998; Gailliot et al., 2007); as a result, people would prefer easier activities, such as entertainment. Third, the levels of activity characteristics were different between the two situations. Compared to the unthreatening situation, in the threatening situation, participants reported lower behavioural experience, sensory experience, affective experience, and spiritual experience, and scored higher frequency in EA. This result indicated that the behavioural pattern in the threatening situation was less effective than the unthreatening situation; the increased frequency was probably a compensatory effort. In fact, the decreased effectiveness in the threatening situation could be foreseen as both the mixed motivations and a narrowed behavioural election could damage the achievement of wellbeing. The findings, to some extent, explained why rebuilding wellness is a difficult issue in human society.

\section{Theoretical and Practical Contributions}

We believe this study has practical and theoretical value. The majority of studies of wellbeing in the past were committed to assessing the levels of wellbeing and aiming to answer whether humans have achieved wellbeing. However, fewer studies have explored how humans can achieve wellbeing and what methods can be applied for it. Specifically, with the trend of juxtaposing hedonic wellbeing and eudaimonic wellbeing, most studies have defined and distinguished these two approaches but indicated no behavioural paths to wellbeing. As a result, our society pays much attention to the issue of wellbeing, but we know little about practical approaches to achieve it. This study, in a practical context, provided the public with various behavioural paths that originate from our daily life and were operable to help us achieve hedonic wellbeing and eudaimonic wellbeing. In particular, this study also discussed the behavioural pattern of rebuilding wellness, and we found that the effectiveness decreased in the process. This could inspire us to regain our lost happiness and meaning.

In the theoretical context, this study distinguished between hedonic and eudaimonic wellbeing from an activity perspective and benefitted a better understanding of these two approaches; activity analysis could also clarify some inconsistent results in wellbeing research. For example, two recent gene studies debated whether the hedonic wellbeing state is harmful to good health (see Brown, MacDonald, Samanta, Friedman, \& Coyne, 2014; Fredrickson et al., 2013). Activity analysis provides a new perspective to understand the controversy: it is possible that both healthy behaviours (such as communication, travel) and unhealthy behaviours (such as smoking, risky sexual behaviour) contribute to hedonic wellbeing. However, these two types of behaviours have adverse effects on health (Boehm \& Kubzansky, 2012). Therefore, the controversy could be attributed to the specific activities that are used to achieve hedonic wellbeing.

\section{Limitations and Future Directions}

There were also limitations in this study. First, the participants in this study were all Chinese undergraduate students, and the demographic factors may influence the interpretation of our results, such as their cultural background, religion, gender, age, and education. For example, some evidence has showed that collectivism and individualism may play important roles in understanding wellbeing (Kitayama, Markus, \& Kurokawa, 2000). The linkages between hedonic wellbeing, eudaimonic wellbeing, and functions such as self-esteem, self-affirmation, and self-concept, are weaker in collectivistic cultures than in individualistic cultures (Church et al., 2014; Nelson, Fuller, Choi, \& Lyubomirsky, 2014; Oishi, Diener, Lucas, \& Suh, 1999). China is deeply influenced by collectivism; thus, it is possible that the participants in this research may have different preferences for wellbeing activities relative to those in individualistic cultures. Cross-cultural studies about wellbeing activity will be appreciated in the future. In addition, there was a gender imbalance in the current sample, insofar as there were substantially more females than males. Prior studies found gender was an influence factor of levels of wellbeing (Fujita, Diener, \& Sandvik, 1991). It is possible that gender also plays a role in the preference of wellbeing activity. More studies on this topic are needed with gender-balanced samples. Second, the representativeness measured the activity use but did not suggest the activity efficiency, and thus there might be a gap between the two concepts. It is possible that the most representative activities were not the most efficient ones. Future research should examine the relation between representativeness and efficiency.

\section{Acknowledgments}

This study was supported by the National Natural Science Foundation of China (Grant No. 31600910). We would like to thank Prof. Chi-Yue Chiu, Prof. Ying-yi Hong, Dr Lin Qiu, and Dr Lingnan He for their helpful comments on earlier drafts of this article and the thoughtful editor and reviewers who helped us improve this manuscript even further.

\section{References}

Bauer, J.J., \& McAdams, D.P. (2010). Eudaimonic growth: Narrative growth goals predict increases in ego development and 
subjective well-being 3 years later. Developmental Psychology, 46, 761-772.

Bauer, J.J., McAdams, D.P., \& Pals, J.L. (2008). Narrative identity and eudaimonic well-being. Journal of Happiness Studies, 9, 81-104.

Baumeister, R.F., Bratslavsky, E., Muraven, M., \& Tice, D.M. (1998). Ego depletion: Is the active self a limited resource? Journal of Personality and Social Psychology, 74, 1252-1265.

Baumeister, R.F., Vohs, K.D., Aaker, J.L., \& Garbinsky, E.N. (2013). Some key differences between a happy life and a meaningful life. The Journal of Positive Psychology, 8, 505516.

Biswas-Diener, R., Kashdan, T.B., \& King, L.A. (2009). Two traditions of happiness research, not two distinct types of happiness. The Journal of Positive Psychology, 4, 208-211.

Boehm, J.K., \& Kubzansky, L.D. (2012). The heart's content: The association between positive psychological well-being and cardiovascular health. Psychological Bulletin, 138, 655-691.

Brakus, J.J., Schmitt, B.H., \& Zarantonello, L. (2009). Brand experience: What is it? How is it measured? Does it affect loyalty? Journal of Marketing, 73, 52-68.

Brehm, J.W. (2007). A brief history of dissonance theory. Social and Personality Psychology Compass, 1, 381-391.

Brown, N.J., MacDonald, D.A., Samanta, M.P., Friedman, H.L., \& Coyne, J.C. (2014). A critical reanalysis of the relationship between genomics and well-being. Proceedings of the National Academy of Sciences, 111, 12705-12709.

Burke, B.L., Martens, A., \& Faucher, E.H. (2010). Two decades of terror management theory: A meta-analysis of mortality salience research. Personality and Social Psychology Review, 14, 155-195.

Cahn, S.M. (1990). Classics of Western philosophy (3rd ed.). Indianapolis, IN: Hackett.

Church, A.T., Katigbak, M.S., Ibáñez-Reyes, J., de Jesús VargasFlores, J., Curtis, G.J., Tanaka-Matsumi, J., Simon, J.Y.R. (2014). Relating self-concept consistency to hedonic and eudaimonic well-being in eight cultures. Journal of CrossCultural Psychology, 45, 695-712.

Delle Fave, A., Brdar, I., Freire, T., Vella-Brodrick, D., \& Wissing, M.P. (2011). The eudaimonic and hedonic components of happiness: Qualitative and quantitative findings. Social Indicators Research, 100, 185-207.

Dewey, J. (2002). Human nature and conduct. North Chelmsford, MA: Courier Corporation.

Diener, E., Lucas, R.E., \& Scollon, C.N. (2006). Beyond the hedonic treadmill: Revising the adaptation theory of well-being. American Psychologist, 61, 305-314.

Diener, E., Sapyta, J.J., \& Suh, E. (1998). Subjective well-being is essential to wellbeing. Psychological Inquiry, 9, 33-37.

Dubé, L., \& Le Bel, J. (2003). The content and structure of laypeople's concept of pleasure. Cognition \& Emotion, 17, 263-295.

Emmons, R.A., \& McCullough, M.E. (2003). Counting blessings versus burdens: An experimental investigation of gratitude and subjective wellbeing in daily life. Journal of Personality and Social Psychology, 84, 377-389.
Fredrickson, B.L. (2001). The role of positive emotions in positive psychology: The broaden-and-build theory of positive emotions. American Psychologist, 56, 218-226.

Fredrickson, B.L., Grewen, K.M., Coffey, K.A., Algoe, S.B., Firestine, A.M., Arevalo, J.M.G., et al. (2013). A functional genomic perspective on human well-being. Proceedings of the National Academy of Sciences, 110, 13684-13689.

Fujita, F., Diener, E., \& Sandvik, E. (1991). Gender differences in negative affect and well-being: The case for emotional intensity. Journal of Personality and Social Psychology, 61, 427-434.

Gailliot, M.T., Baumeister, R.F., DeWall, C.N., Maner, J.K., Plant, E.A., Tice, D.M., Schmeichel, B.J. (2007). Self-control relies on glucose as a limited energy source: Willpower is more than a metaphor. Journal of Personality and Social Psychology, 92, 325-336.

Gallagher, M.W., Lopez, S.J., \& Preacher, K.J. (2009). The hierarchical structure of well-being. Journal of Personality, 77, 1025-1049.

Glaser, B.G., \& Strauss, A.L. (2009). The discovery of grounded theory: Strategies for qualitative research. Piscataway, NJ: Transaction Publishers.

Gu, D., Huang, N., Zhang, M., \& Wang, F. (2015). Under the dome: Air pollution, wellbeing, and pro-environmental behaviour among Beijing residents. Journal of Pacific Rim Psychology, 9, 65-77.

Hart, J., Shaver, P.R., \& Goldenberg, J.L. (2005). Attachment, self-esteem, worldviews, and terror management: Evidence for a tripartite security system. Journal of Personality and Social Psychology, 88, 999-2013.

Heine, S.J., Proulx, T., \& Vohs, K.D. (2006). The meaning maintenance model: On the coherence of social motivations. Personality and Social Psychology Review, 10, 88-110.

Henderson, L.W., Knight, T., \& Richardson, B. (2013). An exploration of the well-being benefits of hedonic and eudaimonic behaviour. The Journal of Positive Psychology, 8, 322-336.

Huta, V., \& Ryan, R.M. (2010). Pursuing pleasure or virtue: The differential and overlapping well-being benefits of hedonic and eudaimonic motives. Journal of Happiness Studies, 11, $735-762$.

Huta, V., \& Waterman, A.S. (2014). Eudaimonia and its distinction from hedonia: Developing a classification and terminology for understanding conceptual and operational definitions. The Journal of Happiness Studies, 15, 1425-1456.

Joshanloo, M. (2011). Investigation of the contribution of spirituality and religiousness to hedonic and eudaimonic wellbeing in Iranian young adults. Journal of Happiness Studies, 12, 915-930.

Kahneman, D. (1999). Objective happiness. In D. Kahneman, E. Diener, \& N. Schwartz (Eds.), Well-being: The foundations of hedonic psychology (pp. 3-25). New York, NY: Russell Sage.

Keyes, C.L., Shmotkin, D., \& Ryff, C.D. (2002). Optimizing wellbeing: The empirical encounter of two traditions. Journal of Personality and Social Psychology, 82, 1007-1022.

Kimiecik, J. (2011). Exploring the promise of eudaimonic wellbeing within the practice of health promotion: The 'how' is 
as important as the 'what'. Journal of Happiness Studies, 12, 769-792.

Kitayama, S., Markus, H.R., \& Kurokawa, M. (2000). Culture, emotion, and well-being: Good feelings in Japan and the United States. Cognition \& Emotion, 14, 93-124.

Lambird, K.H., \& Mann, T. (2006). When do ego threats lead to self-regulation failure? Negative consequences of defensive high self-esteem. Personality and Social Psychology Bulletin, $32,1177-1187$.

Liu, L. (2008). To have and to be: Towards the social representation of quality of life in China. Journal of Community \& Applied Social Psychology, 18, 233-252.

McCullough, M., Pargament, K., \& Thoresen, C. (Eds.). (2000). Forgiveness: Theory, research and practice. New York, NY: Guilford Press.

Myers, D.G. (2000). The funds, friends, and faith of happy people. American Psychologist, 55, 56-67.

Nelson, S.K., Fuller, J.A., Choi, I., \& Lyubomirsky, S. (2014). Beyond self-protection self-affirmation benefits hedonic and eudaimonic well-being. Personality and Social Psychology Bulletin, 40, 998-1011.

Norton, D. (1976). Personal destinies. Princeton, NJ: Princeton University Press.

Oishi, S., Diener, E.F., Lucas, R.E., \& Suh, E.M. (1999). Crosscultural variations in predictors of life satisfaction: Perspectives from needs and values. Personality and Social Psychology Bulletin, 25, 980-990.

Peterson, C., Park, N., \& Seligman, M.E. (2005). Orientations to happiness and life satisfaction: The full life versus the empty life. Journal of Happiness Studies, 6, 25-41.

Pinker, S. (1999). How the mind works. Annals of the New York Academy of Sciences, 882, 119-127.

Proulx, T., \& Inzlicht, M. (2012). The five 'A's of meaning maintenance: Finding meaning in the theories of sense-making. Psychological Inquiry, 23, 317-335.

Ryan, R.M., \& Deci, E.L. (2001). On happiness and human potentials: A review of research on hedonic and eudaimonic well-being. Annual Review of Psychology, 52, 141-166.

Ryan, R.M., Huta, V., \& Deci, E.L. (2008). Living well: A selfdetermination theory perspective on eudaimonia. Journal of Happiness Studies, 9, 139-170.

Ryff, C.D. (2013). Psychological well-being revisited: Advances in the science and practice of eudaimonia. Psychotherapy and Psychosomatics, 83, 10-28.

Ryff, C.D., \& Singer, B.H. (2008). Know thyself and become what you are: A eudaimonic approach to psychological well-being. The Journal of Happiness Studies, 9, 13-39.
Seligman, M.E.P., Steen, T.A., Park, N., \& Peterson, C. (2005). Positive psychology progress: Empirical validation of interventions. American Psychologist, 60, 410-421.

Shepherd, S., Kay, A.C., Landau, M.J., \& Keefer, L.A. (2011). Evidence for the specificity of control motivations in worldview defense: Distinguishing compensatory control from uncertainty management and terror management processes. Journal of Experimental Social Psychology, 47, 949958.

Simpson, J.A., Ickes, W., \& Grich, J. (1999). When accuracy hurts: Reactions of anxious-ambivalent dating partners to a relationship-threatening situation. Journal of Personality and Social Psychology, 76, 754-769.

Staw, B.M., Sandelands, L.E., \& Dutton, J.E. (1981). Threat rigidity effects in organizational: A multilevel analysis. Administrative Science Quarterly, 26, 501-524.

Steger, M.F., Kashdan, T.B., \& Oishi, S. (2008). Being good by doing good: Daily eudaimonic activity and well-being. Journal of Research in Personality, 42, 22-42.

Steger, M.F., \& Shin, J.Y. (2012). Happiness and meaning in a technological age: A psychological approach. In P. Brey, A. Briggle, \& E. Spence (Eds.), The good life in a technological age (pp. 92-108). New York, NY: Routledge.

Ward, T.B. (1994). Structured imagination: The role of conceptual structure in exemplar generation. Cognitive Psychology, 27, 1-40.

Ward, T.B. (1995). What's old about new ideas? In S.M. Smith, T.B. Ward, \& R.A. Finke (Eds.), The creative cognition approach (pp. 157-178). Cambridge, MA: MIT Press.

Ward, T.B., Patterson, M.J., Sifonis, C.M., Dodds, R.A., \& Saunders, K.N. (2002). The role of graded category structure in imaginative thought. Memory \& Cognition, 30, 199216.

Ward, T.B., Smith, S.M., \& Vaid, J.E. (1997). Creative thought: An investigation of conceptual structures and processes. Washington, DC: American Psychological Association.

Waterman, A.S., Schwartz, S.J., \& Conti, R. (2008). The implications of two conceptions of happiness (hedonic enjoyment and eudaimonia) for the understanding of intrinsic motivation. Journal of Happiness Studies, 9, 41-79.

Waterman, A.S. (1993). Two conceptions of happiness: Contrasts of personal expressiveness (eudaimonia) and hedonic enjoyment. Journal of Personality and Social Psychology, 64, 678-691.

Xin-qiang, W., Xiao-xin, H., Fan, Y., \& Da-jun, Z. (2016). Structure and levels of meaning in life and its relationship with mental health in Chinese students aged 10 to 25. Journal of Pacific Rim Psychology, 10, e10. 